Check for updates

The BMJ

Cite this as: BMJ 2021;374:n2254 http://dx.doi.org/10.1136/bmi.n2254 Published: 14 September 2021

\title{
Covid-19: Vaccinating children will help end pandemic, says minister
}

\section{Gareth lacobucci}

Offering 12-15 year olds covid vaccination is the way out of the pandemic, the vaccine deployment minister, Nadhim Zahawi, has said.

The government confirmed on 13 September that it had accepted advice from the four UK chief medical officers and that in England children aged 12 to 15 should be offered one dose of the Pfizer and BioNTech vaccine. Schools will deliver the programme, with invitations for vaccination starting next week. The other UK countries were expected to act similarly.

Zahawi said that the CMOs' recommendation was made "on the basis of the benefits to children alone and not the benefits to adults or wider society."

The CMOs were asked by ministers to review the wider benefits of vaccinating 12-15 years olds after the UK's Joint Committee on Vaccination and Immunisation recommended, purely on health grounds, against universal vaccination of this age group. ${ }^{1}$

The CMOs agreed unanimously that vaccinating children was warranted on "public health grounds" after considering the effect vaccination would have on transmission in schools and on children's education. ${ }^{2}$ They concluded that the "additional likely benefits of reducing educational disruption, and the consequent reduction in public health harm from educational disruption, on balance provide sufficient extra advantage in addition to the marginal advantage at an individual level identified by the JCVI to recommend in favour of vaccinating this group."

Zahawi told BBC Radio 4 on 14 September that he hoped vaccinating children would "be the last piece in the jigsaw to move from pandemic to endemic."

Parents, guardians, or carers will be asked to consent to vaccination in line with existing school vaccination programmes. Where parents and children disagree over vaccination they will be invited to discuss the issue with their GP. If there is no consensus, then as long as a child is considered to be Gillick competent then they will be able to decide for themselves, said Zahawi.

He told MPs, "Whatever decision teenagers and parents take, they must be supported and not stigmatised in any way. We must continue to respect individual choice.”

Zahawi acknowledged that people may have more questions when it comes to vaccinating their children. He said, "But to those who remain undecided, I want to say this: the MHRA is the best medical regulator in the world-and they have rigorously reviewed the safety of our vaccines. They have concluded they are safe for 12 to 15 year olds."

Russell Viner, professor of child and adolescent health at University College London, described the announcement as a "good decision for young people and for broader society." He said, "Vaccinating 12-15 year olds remains a very marginal balance in medical terms, although with over 10 million teenagers vaccinated worldwide we are now much clearer about safety in this age group."

In a statement the Royal College of Paediatrics and Child Health said vaccination could benefit healthy children by minimising disruption to their schooling, allowing them to mix more freely with their friends and giving more protection to friends and family. But it added, "Children, young people, and all of society will directly benefit from an increase in vaccination uptake in the adult population, particularly by those in their 20s, 30s, and 40s. Tackling this pandemic, which is still ongoing, does not depend on vaccinating children, who have already borne a great deal on behalf of us all."

The college also said, "It is extremely important that any covid-19 vaccination programme in schools does not interfere in any way with other school vaccination programmes where the health benefits are more clear cut and have the potential to be lifesaving."

Speaking at The BMJ's recent webinar on vaccinating children, Adam Finn, professor of paediatrics at the University of Bristol, cautioned, "Taking away the people who normally immunise children with other vaccines to do this may further disrupt these programmes. It could ultimately result in more deaths from cervical cancer, meningitis, and flu. You can't do something without not doing something else."

The JCVI should advise on whether second doses may be necessary next year, once more international data were available, the CMOs said.

lacobucci G. Covid-19: JCVI opts not to recommend universal vaccination of 12-15 year olds. BMJ 2021;374:n2180.

doi: 10.1136/bmj.n2180 pmid: 34479872

2 Department of Health and Social Care. Universal vaccination of children and young people aged 12 to 15 years against covid-19: letter from the UK chief medical officers to the UK health ministers on covid-19 vaccination of 12 to 15 year olds. 13 Sep 2021. https://www.gov.uk/government/publications/universal-vaccination-of-children-and-young-people-aged-12-to15-years-against-covid-19.

This article is made freely available for use in accordance with BMJ's website terms and conditions for the duration of the covid-19 pandemic or until otherwise determined by BMJ. You may use, download and print the article for any lawful, non-commercial purpose (including text and data mining) provided that all copyright notices and trade marks are retained. 